\title{
APICULTURA Y ORGANIZACIONES DE APICULTORES ENTRE LOS MAYAS DE YUCATÁN
}

\author{
Margarita Rosales González y Amada Rubio Herrera \\ Centro INAH Yucatán
}

\begin{abstract}
Resumes: En las comunidades mayas la apicultura continúa siendo una actividad relevante pero complementaria, cuya lógica y condiciones de producción se contraponen a las nuevas normas del mercado internacional. La integración de organizaciones apícolas se considera una estrategia para la "modernización" de la apicultura y la comercialización de la miel en mejores condiciones. Este trabajo se refiere al sentido que tanto la apicultura como estas organizaciones tienen para sus integrantes, a sus expectativas, intereses, aprendizajes y a la forma en que se relacionan con instituciones y agentes externos. El escrito se basa en entrevistas y observaciones realizadas en 12 organizaciones apícolas durante 2005 y 2006 en el marco del proyecto de investigación del centro INAH Yucatán "Organizaciones indigenas y procesos de desarrollo en comunidades mayas del sur de Yucatán".
\end{abstract}

PALABras CLAVE: apicultura, organizaciones, apicultores, comunidades mayas.

Aвstract: In Mayan communities, beekeeping continues to be an important but complementary activity, whose logic and conditions of production are opposed to the new norms of the international market. The integration of apicultural organizations is considered as a strategy for the "modernization" of beekeeping and the commercialization of the honey in better quality. The present research deals with the meaning that beekeeping has for the members of such organizations, and it explores the expectations, interests and training processes of the members, analyzing finally how are the relationships between these organizations and external agents and institutions. The research is based on interviews and observations made in 12 apicultural organizations between 2005 and 2006, as part of the research project of the INAH Regional Center Yucatan, entitled "Indigenous Organizations and Processes of Development in Mayan Communities in Southern Yucatan".

KFrwords: apicultural, organizations, beekeeping, maya communities.

REc.praón: 13 de noviembre de 2007.

ACIPTACOÓN: 25 de noviembre de 2008 . 



\title{
APICULTURA Y ORGANIZACIONES DE APICULTORES ENTRE LOS MAYAS DE YUCATÁN
}

\author{
Margarita Rosales González y Amada Rubio Herrera
}

Centro INAH Yucatán

\section{Introduccion: la apicultura entre los mayas}

La miel y la cera han estado presentes en la vida cotidiana de los mayas peninsulares desde la época prehispánica hasta nuestros días, si bien la cría de las abejas meliponas (Melipona beechii) no ha tenido el mismo sentido y finalidad que la cría de abejas europeas introducida y adaptada en América ${ }^{1}$ (Apis mellifera) que predomina en la actualidad.

La renombrada calidad y agradable sabor de la miel de las diversas variedades de abejas nativas está ampliamente documentada al igual que su abundancia y la existencia de innumerables criaderos en las poblaciones mayas prehispánicas, así como su subsecuente presencia durante la Colonia y su utilización para el pago de tributos y para comercializar (Terrones, 1994, Landa, 1973, Cogolludo, Oviedo y Valdez en Terrones, 1994: 45-46)

En la primera mitad del siglo xx, Redfield y Villa Rojas (1964) y Villa Rojas (1978) corroboran la importancia y presencia de las meliponas y sus distintas variedades en las comunidades mayas de entonces, donde la mayor parte de los hombres las criaban y los productos de las colmenas eran utilizados en las prácticas religiosas: miel para la bebida ceremonial, balché o saka' y cera para las velas de las ofrendas. Pero la miel tenía también un uso medicinal altamente apreciado y servía para endulzar las bebidas antes de la introducción del azúcar como hacían los abuelos de los actuales apicultores.

La cría de meliponas era y es un trabajo muy delicado, poco parecido al de la abeja europea, sobre todo por los rituales y cuidados con los que se les trata, ya que requieren menos "prácticas productivas" pero una mayor reverencia y prác-

\footnotetext{
${ }^{1}$ Esta abeja fue introducida en las colonias inglesas de Norteamérica en el siglo xvı y se tienen noticias de su presencia en México en 1764 (Calkins, 1975: 2003 en Merril, 1984). También se le conoce como abeja americana por su gran adaptación al medio. En los últimos 20 años ha sufrido un proceso de africanización al cruzarse con abejas más agresivas provenientes de una población híbrida africanizada que se originó en Brasil; si bien no toda la población ha sido afectada de manera semejante. En este trabajo usaremos el término de abeja europea para la Apis mellifera por ser este su origen, pero como en las comunidades mayas es más conocida como abeja americana se mantendrá este término en las citas textuales.
} 
ticas rituales. Las abejas tienen deidades que las cuidan y a las que pertenecen los apiarios, al igual que el monte. Al realizar los rezos y las ofrendas, el hombre es perdonado por tomar su miel (y por tocar a sus insectos). Esto explica el extremo cuidado que se tenía al extraer la miel ${ }^{2}$ y también el hecho de no cosecharla toda. Por cada cosecha se debe ofrecer comida a los dueños ( $u$ hanli cab) y agradecer la colecta, de lo contrario el apicultor puede enfermarse y en ese caso la ceremonia se realiza para reparar el daño, para sanar. La segunda ceremonia $u$ hedz luumil cab es para mover las colmenas ${ }^{3}$ (jobones) o cuando se añade una colmena (Redfield y Villa Rojas, 1962).

Y es esta forma de tratarlas y de utilizar su miel, en el marco de la concepción maya del uso y cuidado de los recursos naturales, lo que le da un sentido muy diferente a la meliponicultura de la apicultura actual. La miel de ambas es incluso de naturaleza distinta, la miel nativa es muy caliente y apropiada para personas debilitadas por enfermedades o partos, y la de la abeja "extranjera" se considera fría y peligrosa para parturientas (Merril Sands, 1984: 230). Tec y Boccara (1980), reportan incluso un cierto desprecio por la abeja europea en la localidad de Tabi, al considerar que "agarran cualquier suciedad para hacer su miel, en cambio las del país son más limpias", comentarios que también se han escuchado en otras comunidades del sur del estado (apicultor de Chacsinkin, 2006).

De manera que cuando se generalizó la introducción de la abeja europea en las selvas tropicales de la península en la segunda mitad del siglo $\mathrm{xx}$ y fue adoptada ampliamente por los campesinos mayas, no se trató de una simple sustitución de especies o de la persistencia de una actividad ancestral, hubo un cambio de sentido profundo. Esta miel se tomó como un producto prioritariamente comercial que permitía obtener los ingresos monetarios que la milpa ya no proporcionaba. Fuera por esta adopción y preferencia, porque fuera abatida, o ahuyentada por una especie más agresiva y dominante, la población de abejas nativas y su cría disminuyó drásticamente y en la actualidad son pocos los hombres o mujeres mayas que la trabajan. "Quien sabe por que se fueron $[\ldots]$ en la montaña $[\ldots]$ otros campesinos dicen haber visto peleas de las abejas del monte contra las abejas extranjeras $[\ldots \mid$ y las abejas del monte morían o huían a las montañas" (Tec y Bocara, 1980: 6).

Ello explica en parte, el escaso consumo de miel en Yucatán (300 mg per cápita al año) y en las comunidades mayas, el cual es más bajo que el promedio nacional, debido también al prestigio que conlleva el azúcar:

mi papa tenía (meliponas) no hay que alimentarlas $[\ldots]$ casi no tomábamos azúcar esa miel se usaba, [...] algunos decían 'esa gente es pobre, no tiene dinero para

\footnotetext{
${ }^{2}$ Si una abeja caía en la miel, se le limpiaba y secaba; si una abeja se ahogaba en la miel, se le enterraba envuelta en una hoja.

${ }^{3}$ Las colmenas sólo se debían de mover los sábados, pues ese día, al igual que los hombres, las abejas descansan y se hallan todas en la colmena. Si un apiario se cambiaba de lugar, había que avisar al "gran señor de las abejas" para que enviara a los cuidadores o deidades menores a proteger el apiario.
} 
comprar azúcar' [...] luego quedó maña de que uno tome azúcar $[\ldots]$ y ahora no usamos la miel para endulzar (apicultor de Hocabá, Yucatán, 2007).

Cuando se trabaja con la abeja "americana" no se realizan las ceremonias y ofrendas efectuadas a los "señores" pero es que en general "ya casi no se saca comida ni en la milpa" (apicultor de Hocabá, 2007). En cambio en comunidades del sur se llega a ofrecer saká en el terreno donde se coloca el apiario especialmente cuando las hormigas están atacando a las abejas.

Este cambio de sentido de la apicultura, no significa que la cría de abejas europea no sea una actividad productiva compatible y complementaria con la milpa y con el manejo diversificado del monte. Ello explica también esta amplia adopción de la misma entre los mayas peninsulares en la década de los setenta como una actividad que con relativamente poco trabajo y cuidado de las abejas, proveía de ingresos monetarios a las familias campesinas.

Treinta años más tarde las condiciones y exigencias del mercado internacional han cambiado al igual que los requerimientos técnicos de la apicultura y del manejo eficiente de una abeja en muchos casos africanizada. No así la lógica y las condiciones de producción de los apicultores mayas que difícilmente pueden ajustarse a la nueva normatividad y lógica empresarial imperante.

Ante ello, tanto instituciones gubernamentales como asociaciones civiles que promueven el desarrollo han considerado la integración de organizaciones apícolas como una estrategia para la "modernización" y capacitación de los pequeños apicultores y la comercialización de la miel en mejores condiciones. El objetivo de este trabajo es entonces ahondar en el sentido que tanto la apicultura como estas organizaciones apícolas tienen para sus integrantes desde su propia visión, expectativas, intereses y aprendizajes, que difieren de las visiones y expectativas de los agentes externos que las promueven.

En el apartado II se refieren las condiciones en las que los campesinos mayas adoptaron la apicultura comercial y la lógica que han seguido en el manejo y recolección de la miel, anotando aspectos de su situación actual. El III trata sobre la integración de las organizaciones apícolas desde la perspectiva y metodología de los agentes externos que las han promovido y en el IV se presentan diversas organizaciones de apicultores mayas actuales, sus orígenes y principales características y se ahonda en las motivaciones, logros y capacidades adquiridas de los apicultores socios de acuerdo con la forma en que se integraron.

Los datos presentados provienen de entrevistas abiertas y observaciones de campo realizadas en 12 organizaciones avícolas, ${ }^{4}$ durante 2005 y 2006 como

\footnotetext{
4 Estas organizaciones son los Grupos Ganaderos de Validación y Transferencia de Tecnología (Gavart's) de Apicultura de comisarías de Mérida: Tajonal (Molas y Cosgaya) y Tzalam (Sierra Papacal y San Ignacio Tesip), las cooperativas Lool Jabin de Holcá, Lool Cab de Hocabá, Lool Jabin de Chacsinkin, San Andrés de Mayapán, Flor de Tajonal de Chacsinkin, Tumben llaj Cab de Sabacché, Lool Chacá de Kimbilá, la Cooperativa de Kantunil, la Sociedad de Solidaridad Social Dzidzilché de Chacsinkin y la Cooperativa Lool Jabin de Tankuché, Calkini, Campeche.
} 
parte del proyecto de investigación del Centro INAH Yucatán "Organizaciones indígenas y procesos de desarrollo en comunidades mayas del sur de Yucatán". ${ }^{5}$ También se realizaron entrevistas a asesores técnicos y promotores de tres organizaciones no gubernamentales (Ong's) para el desarrollo e instituciones de gobierno que trabajan con apicultores. ${ }^{6}$ Por último se hicieron breves visitas para conocer cuál era la situación de 8 organizaciones apícolas en julio del $2009^{7}$ y se entrevistó al directivo de una cooperativa que exporta miel orgánica de organizaciones apícolas en el marco del comercio justo.

\section{La apicultura comercial entre los mayas: origen y situación actual}

Como lo refiere acuciosamente la investigación de Merril Sands (1984: 149), la abeja europea fue introducida a Yucatán a principios del siglo xx por hacendados y profesionistas que experimentaron ampliamente con técnicas de manejo y cría de la misma. A fines de los cuarenta y hasta mediado de los sesenta la producción de miel fue un próspero negocio de empresarios de la elite yucateca que tenían una alta productividad. ${ }^{8}$

La abundante flora, la baja densidad de apiarios y su ubicación en tierras ejidales del oriente y del sur rentadas a bajo costo y el pago de salarios bajos a los campesinos mayas que los cuidaban fueron factores clave que contribuyeron a la condición anterior $(\mathrm{lbid}$.). La demanda del mercado internacional y el alto precio que alcanzó la miel, propiciaron este primer auge de la apicultura empresarial y de las primeras casas exportadoras y empresarios extranjeros importadores que financiaban a los primeros.

Sin embargo, hacia mediados de los sesenta y durante los setenta, varios factores propiciaron un cambio en las unidades de producción capitalistas predominantes y la amplia adopción de la apicultura por los campesinos mayas. Con la baja del precio de la miel y la disminución de los rendimientos ante el aumento de la densidad de apiarios en el monte, los grandes empresarios dejaron de obtener las altas ganancias acostumbradas y disminuyeron sus apiarios. Otro factor no menos importante fue la presión de los ejidatarios para recuperar sus tierras y dedicarlas ellos mismos a la apicultura, aumentando la renta o forzando a dejarlas (Ibid.)

\footnotetext{
${ }^{5}$ Proyecto bajo la responsabilidad de la autora y en el cual la antropóloga Amada Rubio colaboró realizando parte de estas entrevistas.

${ }^{6}$ Éstas fueron la Cooperativa Educación, Cultura y Ecología (EDucr), Investigación y Educación Popular y Autogestiva A.C. (IEPA), Acción Popular de Integración Social A.C. (AP1S) (2005) y la Dirección de Desarrollo Económico del Ayuntamiento de Mérida (noviembre 2004).

${ }^{7}$ En este recorrido se contó con la colaboración del técnico apicola bilingüe Roberto Pech de los Santos.

${ }^{s}$ Cada empresario tenía entre entre mil y mil quinientas colmenas y una productividad que sobrepasaba los $60 \mathrm{~kg}$ por colmena, alcanzando los $100 \mathrm{~kg}$.
} 
Un porcentaje ${ }^{9}$ significativo de los primeros apicultores mayas había trabajado con los empresarios y asimilado una tecnología experimentada y adaptada a las condiciones locales y que transfirieron a otros compañeros. Algunos capturaron enjambres en sus montes, otros los tomaron de las tierras ejidales o adquirieron el equipo que les vendían los empresarios a precios módicos ( $I b i d$. ). No contaban con capital, pero sí con su trabajo y con pequeños ahorros o préstamos con los que empezaron poco a poco la cría de abejas. Hacia mediados de los años sesenta y durante los setenta, las unidades campesinas de producción enfrentaban problemas para obtener de la milpa maíz para consumo y para venta y ya no contaban con otras fuentes de ingreso en efectivo como el trabajo en los henequenales, los campos azucareros o la recolección del chicle (Rosales, 1988, Merril Sands, 1984).

La apicultura resultaba una opción altamente compatible con la milpa en comparación con la pequeña ganadería, no competía por la tierra sino que enriquecía el monte y los ciclos de producción, calendarios de trabajo y requerimientos de gastos en efectivo de ambas actividades son complementarias. No suponía un riesgo excesivo, pues se mantenía la diversificación de la unidad de producción familiar y la producción para el consumo. El mercado y la infraestructura requerida ya estaban establecidos y al contar con trabajo y tierra y con una lógica diferente de producción que buscaba obtener ingresos para el consumo familiar, los campesinos mayas podían sortear los altibajos del mercado e incluso obtener excedentes en buenos años, aunque no las ganancias que una empresa capitalista hubiera requerido. De manera que se adoptó cuando ya no era negocio para los empresarios; pero la apicultura era la mejor opción para obtener ingresos monetarios y se consideraba también un ahorro que permitía paliar los efectos de malas cosechas y proveer de una cierta seguridad para el futuro.

Quienes se iniciaron como apicultores en las comunidades, fueron los campesinos ricos con mayores recursos pero también los de estrato medio y bajo que trabajaban con los primeros apicultores. Los rendimientos eran menores que los de los empresarios pero más altos que los promedios actuales. Además, la política estatal de apoyo a los pequeños productores de ese entonces proporcionó crédito y facilidades para adquirir equipo. Muchos apicultores reportan haber iniciado de esta forma la actividad y es importante resaltar que este apoyo periódico de instituciones públicas para adquirir azúcar o equipo sigue presente como algo que esperan y demandan los productores actuales (observaciones, 2005-09).

Hacia 1972 el perfil de los apicultores mayoritarios había cambiado y hacia principios de los ochenta Merril Sands (1984) estimaba que entre 85 y $90 \%$ de los apicultores eran pequeños productores campesinos y un total aproximado de entre 7600 y 9000 . Este porcentaje no ha cambiado sustancialmente si bien han aumentado el número de pequeños apicultores. ${ }^{10}$ Sin embargo, desde esta

\footnotetext{
${ }^{9}$ El 44\% de la muestra estudiada por Merril Sands (1984: 239).

${ }^{10}$ De acuerdo con datos publicados en el Diario de Yucatán (6 de junio, 2005) con base en los proporcionados por las facultades de Economía y de Medicina Veterinaria de la unDY, en Yucatán
} 
época de auge de la apicultura campesina, 1983, las condiciones de producción de la miel se han deteriorado, especialmente en los últimos trece años (Güemes et al. 2003).

Aunado a la baja de los precios internacionales de la miel hay que agregar los huracanes que cíclicamente han ocasionado grandes pérdidas de colmenas, la africanización de las abejas y las nuevas enfermedades como la varroasis. Pero la baja de la producción y de la productividad también se debe a una mayor densidad de apiarios y una menor flora melífera. A esto se suma el que los apicultores no han estado realizando los requerimientos mínimos de reposición de equipo, cambio de reinas, alimentación necesaria, cuidados sanitarios con productos permitidos o mejoras tecnológicas adecuadas a las nuevas condiciones.

El ingreso por la venta se ha destinado a subsanar necesidades del consumo familiar: alimentación, salud, educación y vestido, pero en general no cubre los costos de producción, ${ }^{11}$ por lo que no renuevan el equipo. La apicultura ya no representa la mejor opción de obtener ingresos en efectivo como lo fue cuando no era mucho el trabajo requerido ni los insumos empleados, a la par que la milpa representa cada vez menos una alternativa para las nuevas generaciones.

A los apicultores yucatecos se les ha llamado "sacamieleros" pues se dice que se limitan a extraer la miel de los apiarios sin dedicarles mayor trabajo y se da el caso de apicultores que estando sus colmenas cerca de fuentes de agua y flora abundante, sólo las visitan cuando hay cosecha: "...a la miel que se le llama "la gracia' porque trabajas poco y casi no inviertes y ganas mucho" (apicultor de Chacsinnkin, 2005). Es común escuchar que antes las abejas daban menos trabajo y se cosechaba más miel, ahora debido a las diferentes enfermedades hay que darles más atención. ${ }^{12}$ Esta queja al igual que la resistencia a adoptar técnicas que suponen más trabajo, nuevos insumos y asumir riesgos, resulta algo constante entre los apicultores, sobre todo entre algunos de mayor edad. Al ser una actividad complementaria, el mayor esfuerzo se dedica por lo común a otras actividades.

A este sentido de la apicultura como una actividad a la que se le dedica poco trabajo y de la cual se obtienen ingresos de acuerdo con las condiciones climatológicas hay que añadir precisamente la dependencia de condiciones aleatorias del medio ambiente y ante las cuales el ciclo de pérdidas y recuperaciones de

los pequeños apicultores son 10800 aproximadamente y 16000 en la península (Güemes et al., 2003: 123).

${ }^{11}$ De acuerdo con Güemes-Ricalde en Güemes et al., 2003, tan sólo dos quintas partes del ingreso se destinan al pago de depreciación del equipo apícola. Sin embargo, observaciones de campo indican que esta proporción llega a ser menor o nula sobre todo entre los apicultores con menos colonias. Esta mayoría de apicultores que poseen menos de 40 colonias y por tanto obtienen menos de $1200 \mathrm{~kg}$ de miel al año no recuperan sus costos variables.

${ }^{12}$ Además, las abejas africanizadas "son mañosas" ya que tienden a abandonar las colmenas con más facilidad que las "antiguas" cuando no hay suficiente flora disponible, comentaron apicultores de diversas localidades. 
colmenas se percibe como un ciclo natural repetitivo. Algunos de estos viejos apicultores comentaron cómo con el huracán Gilberto (1986) perdieron sus colmenas, que recuperaron y volvieron a perder con sequías, para de nuevo recuperar y perder cuando pasó el huracán Isidoro (2002). Ciclos que se aceptan como inevitables y pese a los cuales continúan como apicultores "vamos a seguir" (apicultor de Sierra Papacal, 2005).

Otro aspecto importante a destacar es el que se ha construido en torno a la relación gobierno-apicultores en el que ha sido una constante los "apoyos" demandados o brindados de azúcar para alimentar a las abejas o bien los equipos o instrumentos de trabajo que no pueden adquirir. En un inicio se dieron como crédito pero en los últimos sexenios generalmente han sido subsidios que fortalecieron relaciones de clientelismo político y la cultura política prevaleciente de esperar "favores" y/o depender del gobierno o del patrón.

\section{Las organizaciones apícolas como un medio de enfrentar el mercado}

Considerando la dependencia de los apicultores de las empresas exportadoras de miel, sus escasas o nulas ganancias y las diferencias de precios de venta del productor y del exportador, el Estado decidió intervenir (1968-1972) y crear dos cooperativas (Lol cab y Apícola Maya) para controlar la industria de exportación de la miel. Estas cooperativas fueron creadas desde las instituciones de gobierno en nombre de los apicultores y para beneficio de los mismos. Un gran número de apicultores fueron integrados a Apícola Maya como socios, incluso dieron una aportación a la misma y recibieron remanentes durante algunos años al final del ciclo productivo. Sin embargo, los apicultores no tuvieron participación alguna en la integración de estas cooperativas ni ocuparon ningún cargo en las mismas.

Contrariamente a la percepción de los apicultores, estas cooperativas los beneficiaron indirectamente ya que lograron elevar el precio que se les pagaba, bajar los costos de transporte y a partir de que empezaron a operar, la diferencia de precios pagados a los exportadores en comparación con los recibidos por los productores disminuyó considerablemente, de 65\% a 25\%, (Merril Sands, 1984: 175). Es cierto, sin embargo, que los intermediarios o "coyotes" fueron afectados, pero no desaparecieron y muchas veces eran estos quienes entregaban la miel a Apícola Maya. Actualmente, esta cooperativa ha dejado de entregar remanentes para cubrir el costo de su planta procesadora y sus gastos administrativos; pero también se le ha acusado de malos manejos y corrupción a su interior.

Las organizaciones de apicultores han tenido también una importancia política en el estado como base clientelar del partido en el poder, pero justificada ampliamente por un matiz económico. La base política del partido gobernante en Yucatán (con excepción del sexenio 2001-2007), el Partido Revolucionario Institucional (PRI), ha estado en las zonas rurales y los apicultores han sido uno de 
los objetivos principales de la corporativización política en el campo del régimen priista. Es consecuente entonces que durante el periodo en que Acción Nacional (PAN) gobernó en Yucatán, se haya buscado construir y trabajar con nuevos sujetos desligados de las estructuras del PRI y mermar sensiblemente la capacidad económica y política de Apícola Maya, de conocida filiación priista.

Durante el último sexenio en Yucatán, resurge un reiterado interés en la integración y organización de apicultores, esta vez en torno a centros micro regionales de acopio de miel para suplantar a los numerosos acopiadores locales y regionales que habían vuelto a dominar el mercado local y lograr que los productores accedieran a mejores condiciones de comercialización. Para esto, se programó que fueran los propios apicultores quienes administraran dichos centros, al margen de Apícola Maya. Las organizaciones también facilitarían la canalización de recursos y equipo así como la capacitación de los apicultores en los nuevos requerimientos del mercado.

Sin embargo, de nuevo las organizaciones locales fueron integradas desde "afuera" a partir de un proyecto generado en la Secretaría de Desarrollo Social del estado (Sedesol) de Yucatán en 2004-2005, en beneficio de los futuros socios. A éstos se les incorporó a las organizaciones a partir de listas de apicultores no verificadas en campo, incluyendo a algunos que no contaban con colmenas y excluyendo a otros apicultores reales. A los socios se les entregaba su acta, un fondo para acopiar miel y durante un año se les capacitó y acompañó en el acopio y comercialización de la miel; pero después las organizaciones debieron de marchar solas. ${ }^{13}$

Ello ha sido posible para quienes pudieron integrarse y apropiarse de su organización y/o contaban con alguna experiencia previa de organización; pero en otros casos los conflictos internos, la falta de cohesión, liderazgo y consolidación de la organización, no les han permitido operar adecuadamente, continúan dependiendo de los acaparadores regionales o se han repartido el fondo de acopio, desintegrándose como cooperativas.

A finales del 2006, de 14 de las cooperativas integradas 6 no contaban con fondos para acopiar, una ya lo había repartido y de las 7 que estaban acopiando sólo 3 contaban con centros de acopio pero sin la infraestructura suficiente. En el recorrido del 2009 se visitaron cinco de estas organizaciones formadas entre 2004 y 2005 y se encontró que dos habían repartido su fondo y ya no operaban, una más lo repartió pero el líder acopiaba con crédito del exportador y dos continuaban funcionando como organizaciones, utilizando su fondo y vendiendo al mismo exportador regional de origen alemán (Ver Tabla 1).

\footnotetext{
${ }^{13}$ El equipo capacitador, proveniente de una asociación civil con amplia experiencia con organizaciones apícolas, insistió en la necesidad de continuar el acompañamiento de los apicultores mínimo un año más para consolidar los procesos organizativos y la autogestión de los grupos para la comercialización; pero la normatividad de los programas utilizados y los intereses políticos no aprobaron el trabajar más con las mismas organizaciones sino que se crearan nuevas (asesores de Educe Cooperativa y observación de campo, 2005).
} 
Las acusaciones de corrupción o malos manejos, como es frecuente en la cultura política local, tampoco han estado ausentes en las organizaciones así formadas. El aumento de los precios no ha sido significativo pues los "coyotes" o intermediarios locales y regionales han debido de incrementar los suyos, aunque posiblemente hayan sido afectados. Ciertamente los socios de las cooperativas tienen mayores posibilidades de negociar el precio de la miel que cuando dependen de los préstamos del acopiador y se han ahorrado el transporte de su miel a los centros de acopio y los análisis de laboratorio que corren por cuenta del comprador.

Sin embargo, las organizaciones apícolas no tienen condiciones para sustituir a los grandes procesadores y exportadores, ya que no tienen el capital, las relaciones y la capacidad gerencial para realizar todos los trámites y gestiones requeridos, ni cuentan con las plantas procesadoras certificadas que sólo ellos tienen (presidente Educe Cooperativa, 2009). Estos empresarios han resultado los más beneficiados ya que ahora las cooperativas microrregionales son sus proveedores y acopian la miel para sus plantas sin que los exportadores tengan que erogar recursos y adelantos para la compra de miel y acudir a los numerosos coyotes y acaparadores de los pueblos. Los directivos de las cooperativas comentan que invierten sus fondo en acopiar miel y no pueden comprar más ya que la empresa a la que se la entregan les retrasa mucho el pago. Es importante observar que el trabajo de gestión y administración de las directivas generalmente no es remunerado y no se considera dentro de los gastos de operación de las cooperativas ya que mermaría el precio pagado a los productores. Cabría preguntarse si este trabajo no pagado es un subsidio a la comercialización de la miel que beneficia a estas empresas.

Los exportadores obtienen una mejor calidad de la miel comprada al tratar con una organización que les exige a sus socios las prácticas adecuadas para aprobar los exámenes de inocuidad. También han facilitado la certificación orgánica de algunos socios, lo que incrementa el precio de venta y exportación, pero también los costos de producción de los apicultores. ${ }^{14}$ Además uno de estos exportadores de origen alemán tiene la representación no gubernamental en el sistema producto apícola, ${ }^{15}$ lo que lo coloca en una situación ventajosa para establecer relaciones y acceder a programas y fuentes de financiamiento que puede canalizar hacia sus organizaciones proveedoras tanto para la reconversión productiva (miel orgánica) como para equipo y construcción de centros

\footnotetext{
${ }^{14}$ Certificación que no se entrega a la organización en su conjunto ni a los socios sino que conserva la empresa que cuenta con un padrón de proveedores certificados.

${ }^{15}$ Un sistema producto es el conjunto de actores de los diferentes eslabones que conforman una cadena de producción y abarca desde los proveedores de materia prima, insumos y equipos hasta el consumidor final. En los últimos dos sexenios la política estatal del sector agropecuario ha buscado institucionalizar cada sistema producto para que todos sus integrantes tengan una representación no gubernamental que sea el interlocutor y el gestor ante las instituciones de gobierno (com. verbal Carlos Franco, integrante del sistema producto chile, eslabón investigación, 2009).
} 
de acopio estableciendo una nueva relación patrón-cliente (entrevistas y visitas a organizaciones, 2009, ver Tabla 1). ${ }^{16}$

Otra experiencia de asociación de apicultores con la finalidad de mejorar la producción a partir de la adopción de nuevas tecnologías han sido los Grupos Ganaderos de Validación y Transferencia de Tecnología (GGAVATTS) que se han formado en municipios del oriente de Yucatán y en comisarías de la ciudad de Mérida. En este último caso son grupos no constituidos legalmente, de entre 10 y 16 socios, que a invitación del Ayuntamiento de Mérida se han comprometido ha reunirse periódicamente para intercambiar experiencias y recibir capacitación técnica y que cuentan con la asesoría del INIFAP. ${ }^{17}$ Han demandado y gestionado azúcar y equipo y cuando ha sido a crédito lo han cubierto. El poder acceder a mejores precios para la miel ha sido una de sus demandas constantes en los encuentros en los que participan. Consideramos que estos grupos se han creado en diálogo con los promotores que los apoyan en un ambiente de confianza para el trabajo conjunto; si bien la dependencia hacia estos últimos para reunirse y realizar gestiones es notoria (ver Tabla 1).

La apuesta por la organización como una forma de empoderar a los apicultores y mejorar sus condiciones de producción y venta ha sido también la de agencias de desarrollo de la sociedad civil interesadas en promover el desarrollo sustentable. Si bien, en muchos de estos casos, la forma de impulsarlas muestra grandes diferencias ya que se realiza "desde abajo", con la participación de los apicultores, avanzando poco a poco en la construcción de la organización de acuerdo al ritmo e intereses de los socios y elaborando con ellos el o los proyectos a gestionar. ${ }^{18}$

Ejemplos de estas organizaciones apícolas son la Kabit'ah en los Chenes, Campeche (Rosales y Llanez, 2003), la Kabi Jabin en el Poniente de Bacalar (López y Acosta, 2005 ) o Lool K'aax en la región de la Montaña en Campeche (Coello y Vandeweerd, 2005), en tanto organizaciones de segundo nivel que agrupan a apicultores de varias comunidades y han logrado exportar su producción con asesoría de las onc. Entre las organizaciones de apicultores de primer nivel podemos mencionar a "Lool Jabin" de Tankuché, Campeche y en Yucatán a Tumben

${ }^{16}$ Es este el caso de Maya Honey de Izamal, cuyo dueño forma parte de una familia de empresarios alemanes, dos hermanos dedicados a la exportación de la miel en diferentes áreas de la península, mientras la hermana tiene la empresa importadora en Alemania. Esto les permite obtener y ofrecer mejores precios de compra (presidente Educe Coopera, entrevistas directivas apícolas y recorridos de campo, 2009).

${ }^{17}$ La metodología GGanatr se desarrolló en el INIFAP en el año 1985; son grupos de productores de un mismo sistema de producción, organizados para la validación y transferencia de tecnología. La conformación de estos grupos se da con base en un acuerdo voluntario entre sus miembros para llevar a cabo un programa de trabajo común derivado de consensos con los técnicos que los apoyan.

${ }^{18}$ La expresión "desde abajo" se ha usado coloquialmente para diferenciar el trabajo de estas organizaciones civiles muy cercano a los productores y buscando su participación en todos los niveles, del efectuado por instituciones de gobierno que elaboran proyectos de desarrollo "desde arriba" en las oficinas de funcionarios o investigadores, sin la participación de los futuros interesados a quienes se considera "objeto" de estos proyectos y no sujetos de los mismos. 
Ilaj Kab de Sabacché que han trabajado con recursos del PNuD ${ }^{19}$ y a "Lool bé" de Hocabá, las cuales acopian y venden a exportadores con créditos o adelantos obtenidos (Ver Tabla 1).

La forma de trabajar con el grupo es un factor clave para el desarrollo o construcción de la organización en tanto sujeto social, sobre todo si se trata de una metodología que propicia o busca el que sean los socios los que tomen decisiones y participen, a diferencia de la imposición o conducción vertical de una organización. Las asociaciones civiles entrevistadas no se limitan a la capacitación técnica o administrativa apropiada o a la elaboración de proyectos productivos del interés de los socios, sino que parten de diagnósticos y planeaciones participativas con los grupos y privilegian el acompañamiento para la organización autogestiva de los mismos. Los comités asesorados han de realizar sus planeaciones y evaluaciones anuales y las normas de participación, manejo de fondos y rendición de cuentas son igualmente promovidas. Ello no significa que la elaboración y aplicación de reglamentos sea algo igualmente aceptado por todos los socios ${ }^{20}$ al igual que los talleres de manejo de conflictos que realizaron algunos asesores.

Aun con metodologías de corte participativo que se aplican con firmeza, los resultados pueden variar dependiendo de características personales del facilitador o del grupo en cuestión. Así, la misma metodología e incluso los mismos capacitadores pueden encontrar respuestas diferentes dependiendo del contexto del grupo y de la comunidad en cuestión. Éste fue el caso de los capacitadores de Educe Cooperativa cuando trabajaron con los apicultores de una comunidad pequeña, integrada y con cohesión social como Holcá en Kantunil que continúa operando, en contraste con Lool Jabin de Chacsinkin, de mayor tamaño e integrada a partir de organizaciones previamente existentes y grupos políticos antagónicos, cuyos socios ya dividieron el fondo de acopio por desconfianza a sus representantes y porque consideraron no obtienen beneficios y prefieren este dinero para satisfacer necesidades inmediatas de consumo.

El trabajar "desde abajo" con la organizaciones apícolas buscando la autogestión de las mismas, no garantiza que los apicultores logren consolidar sus organizaciones y alcancen los objetivos que con ellas se pretende, ya que se ven inmersos en una reglamentación y forma de trabajar muy diferente a la que conocen y ajena en gran medida a su lógica de producción. Al fin y al cabo sigue siendo la visión de los de afuera, la apuesta del $t s^{\prime} u u l^{21}$ para mejorar sus condiciones de vida e integrar empresas sociales.

\footnotetext{
${ }^{19}$ En Sabacché se logró la instalación de un apiario escuela manejado orgánicamente con cooperación de todos los socios, el mejoramiento de las reinas con la adquisición de pies de cria, el aumento de apiarios y producción y un pequeño centro de recepción.

${ }^{20}$ En una de estas organizaciones pese a la norma aceptada de excluir de la cooperativa a los socios que no acudieran a un determinado número de asambleas, no se les comunicaba a los socios su exclusión por ser parientes o conocidos y no ser un comportamiento aceptado en la comunidad.

21 Calificativo maya para designar a los "señores", "extranjeros" o gente no maya o de otro estado.
} 


\section{Significados, expectativas e intereses de los apicultores respecto a las organizaciones apícolas}

La mayor parte de los apicultores no han visto a Apícola Maya como su organización sino como una institución del gobierno o una empresa ajena que les compra su producción de acuerdo con mecanismos de fijación de precio que no comprenden, administrada por el ts'uul (Merril Sands, 1984: 259) a los que se acusa con frecuencia de corrupción o en quienes no confían, si bien también se han establecido relaciones clientelares y de patronazgo con los mismos.

La percepción ha sido que esta empresa se beneficia con el trabajo de los apicultores.

Cuando vamos a Apícola Maya dicen que es nuestra casa, pero eso no es cierto, les pertenece a ellos. Nosotros somos los que estamos pagando por sus carros nuevos, sus camiones, sus viajes a China, todo (lbid: 260) ...cómo sabemos si China realmente está vendiendo miel... nosotros no podemos ir a China para saber si es cierto (Ibid: 261). ${ }^{22}$

Éstos son algunos de los comentarios que revelan la percepción de los apicultores al margen del hecho de que la cooperativa logró regular el mercado en sus inicios y aumentar los ingresos percibidos por la miel.

En relación con las organizaciones apícolas formadas en los últimos diez años, podemos considerar que el fortalecimiento de las mismas así como su apropiación y significado para los apicultores, guardan relación directa con el origen, tamaño y forma de integración y acompañamiento de las mismas (ver Tabla 1). De igual forma estos factores inciden en la visión que tienen los apicultores de su grupo, así como en sus intereses y expectativas, a los que se suman el contexto comunitario y el institucional.

Cuando los grupos son incorporados a partir de propuestas externas, las asociaciones se aprecian como un medio temporal para recibir beneficios materiales o "apoyos" (principalmente equipo, azúcar para alimentar a las abejas y dinero para poder acopiar miel) y, en menor medida, capacitaciones y asesoría especializada. En este sentido, la organización se reduce a una suma de intereses particulares que inciden en la obtención de recursos, limitando de esta forma la visión grupal de trabajo. Como pudimos observar, este tipo de organizaciones son grandes, en cuanto a tamaño, agrupando a más de cincuenta socios de diferentes facciones políticas con sus respectivos líderes. Los ejemplos más representativos al respecto fueron las cooperativas de Mayapán y de Chacsinkin integradas por Sedesol estatal en 2005.

Los logros económicos en la mayoría de los socios se perciben como equipo, azúcar, capacitaciones y se espera un mayor precio para la miel que el que da

\footnotetext{
${ }^{22}$ Extractos de entrevistas realizadas en Chan Kom en 1981 y 1982, traducción de Margarita Rosales.
} 
el coyote y otros "apoyos" obtenidos por un proyecto institucional planeado "desde arriba y desde afuera" sin que implique alguna gestión, esfuerzo, inversión o ahorro del propio grupo. Este sustento externo se sigue esperando en la mayoría de las organizaciones, pero se observa con mayor claridad en aquellas que fueron formadas verticalmente.

En distintas asociaciones apícolas de Yucatán, encontramos que la falta de participación de los socios en la toma de decisiones grupales, así como la poca formación del comité y la escasa vida orgánica del grupo, son variables relacionadas al significado que los apicultores le confieren a su organización y al tipo y duración de la asesoría impartida. En general se ha visto como un medio a través del cual se consiguen recursos y donde algunos pueden llegar a manejar a conveniencia propia las relaciones clientelares y de poder prevalecientes en el contexto de una cultura política a la espera de los "favores" o "apoyos" que el patrón (acopiadores y exportadores) o el gobierno otorgue. En este sentido la vida orgánica de la misma no adquiere mayor importancia ni desde luego el significado que le confieren los asesores externos, los cuales se enfrentan a esta cultura política y a una resistencia "pasiva" caracterizada tanto por la poca atención concedida a las reuniones, como a la casi nula disposición de los socios de recibir capacitaciones para el funcionamiento de la organización como tal (asesora APIS A.C. 2005).

Sin embargo, no necesariamente las organizaciones apícolas integradas a partir de un proyecto exógeno son disfuncionales ya que algunas son apropiadas por sus miembros como ocurrió en Holcá, Yucatán cuando el grupo local decidió separarse de la cabecera municipal de Kantunil, manejar su propio fondo y aprovechar las capacitaciones recibidas. En dicha comunidad, donde existe una mayor cohesión entre los apicultores, éstos valoraron los aprendizajes al ver resultados prácticos, y aunque con dificultades y mucho trabajo no remunerado de la directiva aún continúan acopiando y vendiendo en conjunto.

Las organizaciones integradas por iniciativa de los socios o que tienen claridad de sus objetivos, tienen mayores posibilidades de desarrollarse y, en general, son más bien pequeñas, entre diez y veinte integrantes, los cuales son personas que se conocen o se acoplan en su forma de trabajar y con frecuencia están emparentados.

En estas organizaciones se percibe una mayor apropiación de la misma y su identidad se va conformando en torno a su pertenencia a una cooperativa formada con su esfuerzo y con objetivos establecidos por ellos como la de Tankuché en Campeche. En este tipo de organizaciones las expectativas particulares confluyen en el "salir adelante, mejorando la calidad de la miel, aumentando la producción y vendiendo a mejor precio el producto", a partir de un esfuerzo asumido por la mayoría de los socios.

Los grupos que permanecen operando son los que tienen mayor cohesión y vida orgánica (reuniones periódicas para información y toma de decisiones independientemente del asesor) y que saben a dónde quieren ir. Sin embargo, esta vida orgánica también es resultado de las enseñanzas consistentes y sistemáticas 
del asesor que promueve la participación, la elaboración de planes de trabajo y evaluación anual o semestral de los mismos.

Estos grupos se consideran como el espacio adecuado desde donde los socios, y en especial los directivos, se incorporan a procesos de resocialización y aprendizajes de habilidades técnicas y organizativas para alcanzar su meta. Espacios desde los cuales se tienen mayores posibilidades de impactar al desarrollo comunitario como los apicultores de la Montaña, en Campeche o los de Kabi Jabin en el poniente de Bacalar que lograron fijar el precio de la miel en su región, desplazando así a los intermediarios de la zona (Cfr. Coello y Vandeweerd, 2005 y López y Acosta, 2005)

Desde luego que formar una organización cuyas expectativas vayan más allá de la obtención de beneficios personales de corto plazo, es un proceso difícil en el que resulta crucial la presencia de líderes cuyos intereses se enfoquen más en la procuración del bien colectivo que el individual. Líderes que han participado en procesos de formación y emponderamiento que transforman poco a poco la cultura política clientelar prevaleciente. Al respecto, los apicultores de Camino Real han podido construir una cooperativa enfocada al trabajo colectivo con la que esperan "salir adelante", gracias al liderazgo del promotor de la misma quien solía platicar personalmente con cada apicultor sobre la conveniencia de organizarse. Sin embargo después de siete años aún se depende en gran medida del líder que encuentra dificultades para delegar responsabilidades y tareas en otros socios.

En otros casos se observó que los líderes de las asociaciones no delegaban responsabilidades porque para ellos el grupo también se concibe como la plataforma que les permite entablar relaciones con agentes externos y hacer toda clase de gestiones. Pero también ocurre que son los socios quienes no quieren asumir cargos en la cooperativa ya que implican mucho tiempo y esfuerzo sin retribución alguna y así prefieren no cambiar a los directivos que han trabajado bien, como en Holcá. Algunos de estos líderes y representantes asumen todavía su cargo como un servicio que conlleva un prestigio y el dificil reto de "cumplir" y "sacar adelante" no sólo su periodo administrativo sino a la organización en cuestión y en muchos casos esta dedicación es un factor decisivo para la permanencia y consolidación de una organización.

Un apicultor del municipio de Chacsinkin comentaba que él está consciente de que son varios los elementos que inciden en el funcionamiento adecuado de una organización, siendo tres los más importantes: entendimiento por parte de los socios cuando se les plantea algo (aprendizajes), capacidad de analizar la situación que se les plantea sin aceptar todo lo que se les dice (ser críticos) y asistencia a las reuniones (socio Dzidzilché, 2005).

El punto de los aprendizajes merece mención especial ya que se relaciona con la forma de trabajo que los asesores han empleado para capacitar a las cooperativas y con los procesos de resocialización que implica trabajar como cooperativa (Cfr. Krotz, 1988 y Rosales, 1996). 
De manera que para integrar y formar a una organización, los asesores han de tener una buena formación técnica y/o administrativa, funcional al grupo, pero también resulta de primordial importancia la empatía lograda y el establecimiento de confianza mutua entre asesores e integrantes de las asociaciones. Los promotores técnicos mayas que van de otras regiones o comunidades a capacitar a distintos grupos, son muy apreciados en sus explicaciones y en su trabajo sobre todo si cuentan con un buen nivel técnico y se percibe que también son productores, pero cuando son de la misma comunidad no siempre son reconocidos sus saberes.

En general los socios de las distintas organizaciones recuerdan y aprecian las capacitaciones técnicas que recibieron pero no así las que inciden en la organización, la administración de los recursos o la comercialización, a las que no se refieren expresamente, pero que se pueden rastrear en las prácticas que mantiene el grupo o bien en su visión de futuro. En algunos casos, las dinámicas de animación y evaluación empleadas por los facilitadores fueron aceptadas, pero no por todos, ya que algunos apicultores comentaron que se sentían como niños cuando "jugaban" al igual que se mostraron poco interesados con los temas de derechos humanos.

Es importante resaltar que esta manera de integración no responde a las necesidades inmediatas de los apicultores ni a sus formas tradicionales de organización e implica modificar normas y maneras de trabajar adoptando no sólo técnicas que implican más tiempo y esfuerzo sino un cambio de valores y sentido respecto a la producción apícola individual característica de las comunidades mayas. Ello explica los comentarios de los mismos líderes y representantes de las organizaciones respecto a que "los socios del grupo no participan", "no asisten a las capacitaciones" "sólo están por los recursos" o "no les interesa trabajar" y el hecho de que una de las cooperativas con mayor vida orgánica haya disminuido sus socios de 20 , con los que se constituyó inicialmente, a 13 y recientemente a 6 que son los que trabajan de acuerdo con los requerimientos de la agricultura orgánica y a las reglas que ellos mismos se han impuesto.

No cabe duda que lograr que una organización tenga "vida orgánica" y metas bien definidas es una labor ardua y conjunta que implica además de tiempo compromisos por parte de los apicultores y de los capacitadores. Para varios productores es claro que un grupo no se forma en periodos cortos de tiempo, sino más bien se construye a través de los años a la par que se forman sus integrantes. Algunos líderes y representantes de organizaciones apícolas han perseverado largos años al frente de sus organizaciones o trabajando con las mismas a pesar de innumerables obstáculos, confiando en que de forma conjunta podrán enfrentar las cada vez más difíciles condiciones del mercado de la miel.

Este liderazgo que se gesta con visión y gestión hacia afuera y hacia adentro de más largo plazo, llega a establecer alianzas estratégicas con empresas sociales que realicen la exportación de su miel en el marco del comercio justo ${ }^{23}$ que ofre-

\footnotetext{
${ }^{23}$ La certificación en Comercio Justo implica inspecciones periódicas tanto al interior de la organización apícola para garantizar el funcionamiento democrático de la misma como de la comercializadora, la cual debe cubrir básicamente sus costos de operación y transparentar sus ganancias.
} 
ce un precio generalmente mayor siempre y cuando se garanticen condiciones de equidad, transparencia y democracia tanto entre los productores como con los comercializadores (presidente Educe Cooperativa, 2009).$^{24}$

\section{Consideraciones finales}

Los campesinos mayas fueron capaces de adoptar la apicultura basada en la cría de la abeja de origen europeo, una actividad productiva que había sido introducida y adaptada por empresarios yucatecos pero que era compatible con la milpa y con el manejo diversificado de la selva tropical. Con ella obtuvieron ingresos monetarios para la economía familiar y respondieron a la demanda de la miel en el mercado internacional cuando los grandes empresarios ya no obtenían altas ganancias. Ello gracias a que los milperos contaban con tierras, trabajo y una lógica de producción diversificada distinta y orientada al consumo en la que la cría de la abeja era un componente más al que no había que dedicarle tanto esfuerzo.

Esta lógica de producción continúa prevaleciendo entre los pequeños apicultores mayas "sacamieleros", cuando las condiciones ambientale ${ }^{25}$ y de mercado han cambiado, de manera que difícilmente puede responder al aumento de los requerimientos de trabajo y mejoras tecnológicas, al igual que a las nuevas normas y exigencias de calidad y trazabilidad para la exportación de la miel.

Además, las condiciones de pobreza, falta de capital y precariedad de la economía familiar de los campesinos mayas continúan o se han agravado, y el trabajo asalariado fuera de las comunidades ocupa su tiempo y se ha convertido en una fuente primordial de ingresos monetarios. De manera que muchos de estos apicultores no han realizado las mejoras tecnológicas requeridas.

La organización de los apicultores en cooperativas o en asociaciones que faciliten la adopción de tecnología, la adquisición de equipo y el acopio y venta de miel de mejor calidad, ha sido promovida por instituciones públicas y organizaciones civiles para el desarrollo, con diferentes resultados de acuerdo con la forma en que se han integrado, a la apropiación de estas organizaciones por parte de sus socios y al sentido que le han conferido a su organización. Para una parte considerable de apicultores la organización es tan sólo un espacio para "bajar" y repartir recursos que respondan a necesidades inmediatas de consumo familiar o del ciclo apícola.

Las organizaciones que se originaron a iniciativa de los apicultores o en diálogo y co-gestión con asesores o técnicos capacitadores, han permanecido

${ }^{24}$ Éste es el caso de Kabi Jabin en Quintana Roo que cuenta con certificado de miel orgánica; ha recibido asesoría de Educe A.C y en los años recientes Educe Cooperativa se ha hecho cargo de la exportación de la miel buscando la integración de una cadena productiva del sector social (lbid.)

${ }^{25}$ Al deterioro y pérdida de la selva y la consecuente disminución de la flora melífera se agrega la sequía que se percibe como mayor en estos últimos ciclos. En el recorrido realizado en 2009 fueron constantes las referencias a la pérdida de colonias y a la disminución de la producción de miel debido a la sequía. 
como tales, con una visión de mayor alcance y continúan acopiando miel cuando cuentan con recursos para ello. El tamaño y cohesión social del grupo y de sus comunidades son factores que también favorecen su consolidación. Cuando han contado con algún tipo de acompañamiento o capacitación por varios años, especialmente cuando ésta se ha impartido en maya, de manera práctica y con visitas periódicas a los apiarios, se han adoptado tecnologías como el manejo orgánico de los apiarios, mejorando la cantidad y calidad de la miel.

Sin embargo, las asociaciones formadas verticalmente sin la participación de los futuros socios tienden a desintegrarse o no operan como tales ya que la co-gestión entre socios y asesores supone un trabajo costoso, arduo y lento de organización, de construcción de nuevas prácticas, normas, sentidos y lógicas de producción, de acercamiento de visiones disímiles y a veces contrapuestas. Trabajo que no siempre se puede mantener el tiempo suficiente para lograr la consolidación y autogestión de la organización ya que supone un proceso poco compatible con proyectos gubernamentales que pretendan resultados rápidos y vistosos. ${ }^{26}$

El principal objetivo de los apicultores para organizarse, además de la obtención de recursos, ha sido la comercialización en común para obtener mejores precios. Aquellas que acopian con fondos propios han logrado vender a empresas exportadores y obtener un precio ligeramente superior que si vendieran individualmente y ahorrarse el transporte. Sin embargo, continúan dependiendo de los grandes exportadores o de agentes externos que manejan el complicado mundo del comercio exterior al que difícilmente pueden acceder. Además el acopio y venta en común supone muchas veces un trabajo colectivo no remunerado ya sea de los socios o de las directivas que si bien se realiza para la organización cabe cuestionarse sobre otros beneficiarios de este capital social como los mismos comerciantes y exportadores.

Algunas organizaciones de apicultores mayas de Campeche y Quintana Roo que han tenido momentos de desarrollo y crecimiento pero también de crisis, conflictos y reacomodos, han exportado su miel aprovechando algunos nichos de comercio justo y conjuntando esfuerzos endógenos y exógenos, en alianza con asesores y organizaciones civiles que han jugado un rol dinamizador al lado de los apicultores.

Estas organizaciones y sus directivas han debido apropiarse de un instrumento de nuevo ajeno que supone transformar no sólo prácticas y formas de trabajo sino una cultura política clientelar y paternalista y construir identidades y sujetos colectivos que otros les han propuesto en aras de su desarrollo. Cuando el proceso se ha desarrollado "desde abajo" la organización ha cobrado un nuevo sentido para los apicultores y ha generado liderazgos menos paternalistas con visiones de

\footnotetext{
${ }^{26}$ Ninguna de las 11 organizaciones visitadas en 2009 cuentan actualmente con asesoría o acompañamiento, ocho la tuvieron durante un año o más con distintos resultados, pero que terminó con los proyectos respectivos.
} 
mayor alcance, no sólo de las asociaciones apícolas sino también de las comunidades mayas, sus recursos naturales y su ubicación en la sociedad nacional.

\section{Bibliografia}

Coello, Leticia y Bernard Vandeweerd

2005 "Lol K'aax, Organización Apícola de la Montaña en los Chenes, Campeche," documento de comadep A.C. presentado como ponencia en el "Taller de Análisis sobre Estrategias de Acompañamiento y Asesoría a Organizaciones Productivas Mayas", Centro INaH Yucatán, 3-4 de noviembre, Mérida, Yucatán.

Güemes-Ricalde, Francisco, Carlos Echazarreta-González, Roger Villanueva, Juan Manuel Pat-Fernández y Regino Gómez y Álvarez

2003 "La Apicultura en la Península de Yucatán" en Revista Mexicana del Caribe, Año VIII, no. 16: 117-132, Chetumal, Quintana Roo.

Landa, Diego de

1973 Relación de las cosas de Yucatán, México, Porrúa.

López, Patricia y Alejandra Acosta

2005 "Kabi Jabin, spR de RI., Apicultores Mayas del Poniente de Bacalar, documento de eDucE A.C. presentado como ponencia en el "Taller de Análisis sobre Estrategias de Acompañamiento y Asesoría a Organizaciones Productivas Mayas", Centro INAH Yucatán, 3-4 de noviembre, Mérida, Yucatán.

Krotz, Esteban

1988 "La colectvización ejidal como proyecto de resocialización política" en Krotz E.: Ensayos sobre el cooperativismo social en México, unam-Iztapalapa, México, pp. 89-101.

Merril Sands, Deborah

1984 The Mixed subsistence comercial Production System in the Peasant Economy of Yucatán México: An Anthropological Study in Commercial Beekeeping", tesis doctoral, Faculty of The Graduate School, Cornell University.

Redfield Robert y Alfonso Villa Rojas

1962 Chan Kom, a Maya Village, Chicago and London, The University of Chicago Press.

Rosales González, Margarita

1988 Oxkutzcab, Yucatán, 1900-1960. Campesinos Cambio Agrícola y Mercado. México, Colección regiones de México, inah.

1996 "Construyendo la democracia. Cultura política y resocialización en organizaciones campesinas" en Tejera Gaona (coord.) Antropología Política. Enfoques Contemporáneos, in凡//Plaza y Valdés, México, pp. 587-610. 
Rosales González, Margarita y Genner de Jesús Llanez Ortiz

2003 "La Defensa y la Transformación de un Legado: Organizaciones Indígenas en la Península de Yucatán" en Los Investigadores de la Cultura Maya 11, Vol. II, Campeche, Universidad Autónoma de Campeche.

Tec Poot Josè y Michel Bocara

1980 "Abejas y Hombres de la Tierra Maya" en Boletín de la Escuela de Ciencias Antropológicas de la Universidad de Yucatán, Vol. 7, no. 42: 2-24, Mérida, Escuela de Ciencias Antropológicas de la Universidad de Yucatán.

Terrones González, Enrique

1994 "Apiarios Prehispánicos" en Boletín de la Escuela de Ciencias Antropológicas de la Universidad de Yucatán, Vol. 20, no. 117: 43-57, Mérida, Escuela de Ciencias Antropológicas de la Universidad de Yucatán.

Villa Rojas Alfonso

1978 Los Elegidos de Dios. Etnografía de los Mayas de Quintana Roo, México, Instituto Nacional Indigenista. 


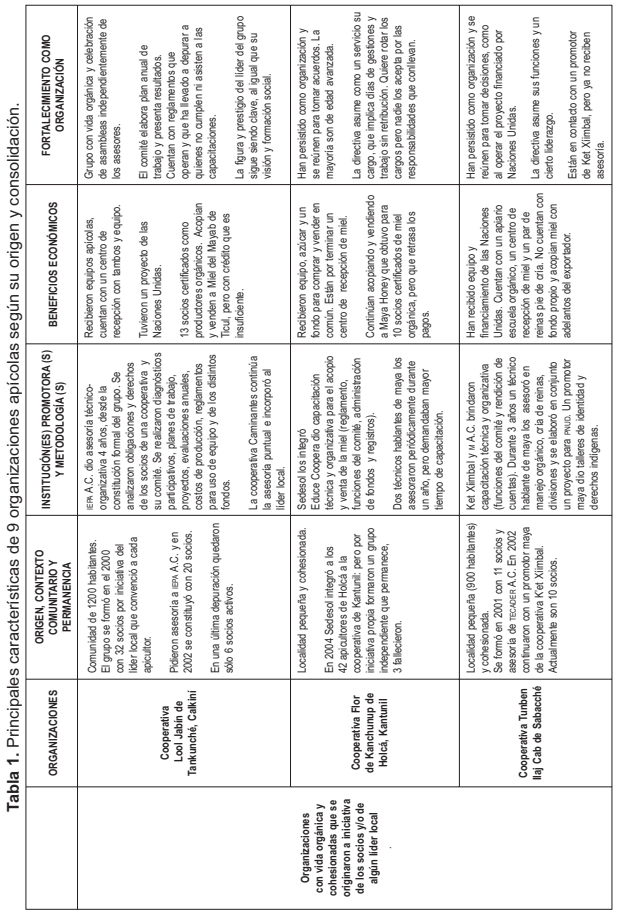




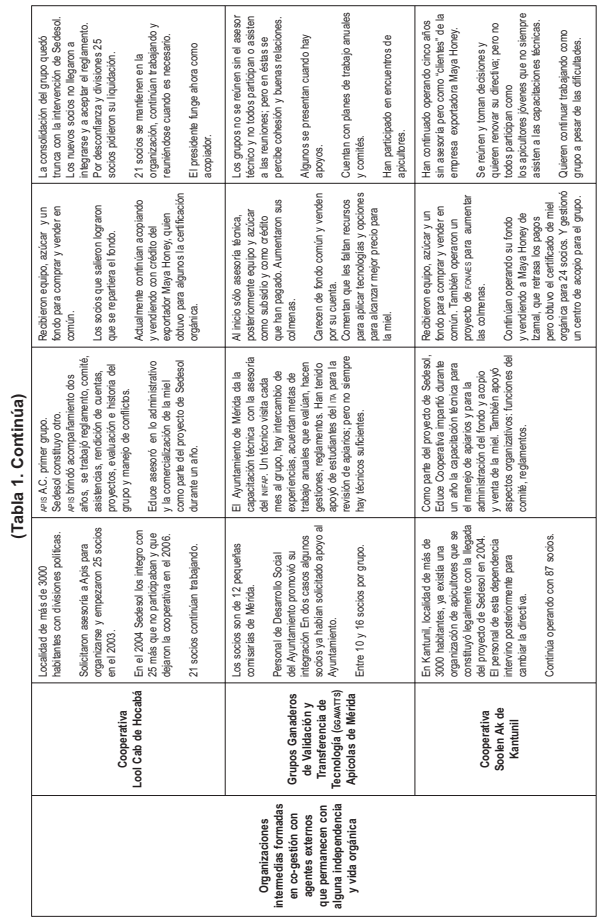




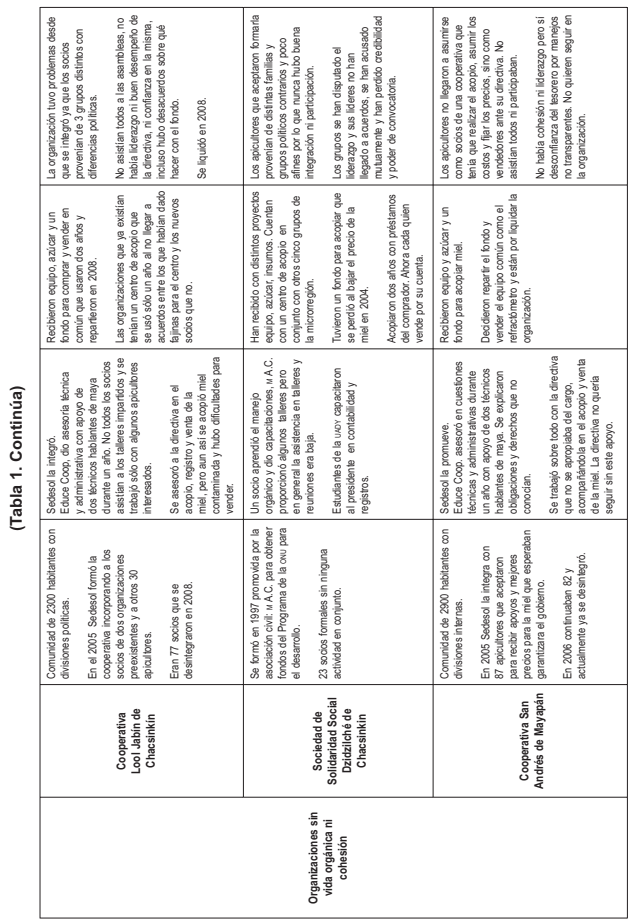

